\title{
O Voto em uma Região Periférica da Cidade de Taubaté-SP
}

\author{
Maria Leticia Juliano Diniz Brito ${ }^{1}$
}

\section{Resumo}

O presente trabalho tem como objetivo compreender o comportamento eleitoral das classes sociais mais pobres, especificamente dos moradores de uma região periférica na cidade de Taubaté - SP. A partir da análise das relações sociais e do espaço onde estes moradores estão inseridos, busca-se responder como os eleitores da região do Cecap decidem e estruturam o seu voto.

A escrita que se segue trata-se de uma pesquisa ainda em andamento e, portanto, o que se pretende é principalmente delinear o objeto deste estudo e os seus resultados parciais. Para tanto, primeiramente iremos abordar um pouco sobre a escolha do local e como o caso foi selecionado. Já em um segundo momento, será mostrado quais técnicas metodológicas utilizadas e como isso vem sendo feito, para finalmente traçarmos os primeiros resultados do trabalho de campo que vem sendo realizado desde setembro de 2013, perpassando o período eleitoral de 2014

Dito isso, uma indagação possível seria: Mas por que estudar especificamente o comportamento eleitoral dos moradores da região periférica do Cecap seria relevante?

A escolha se deu porque os bairros que compõem o Cecap apresentam certa singularidade em relação ao modo que se posicionaram na última

\footnotetext{
1 carolinemdossantos@gmail.com; (16) 9-9740-0839 - Universidade Federal de São Carlos Orientador: Jorge Mattar Villela - Iniciação Cientifica/Monografia
} 
eleição presidencial. Com base no resultado da votação de 2010 obtida em três locais de votação próximos à região ${ }^{2}$, foi possível perceber que o candidato José Serra (PSDB) foi quem mais angariou votos na região (com cerca de 36\%), a candidata Dilma Roussef (PT) ficou em segundo lugar (30\%), seguida por Marina Silva (PV), que obteve $26 \%$.

Partindo do diálogo com a tese Os sentidos do lulismo: reforma gradual e pacto conservador desenvolvida por André Singer, o caso de Taubaté foi escolhido por exemplificar um estudo desviante do padrão, ou seja, por ser um bairro considerado de baixa renda era esperado, como propõe a tese do lulismo, que a candidata do PT tivesse a maioria dos votos e, em contrapartida, o PSDB não fosse o vitorioso devido ao realinhamento ocorrido em 2006.

Como este padrão não foi o verificado, pode-se admitir que o caso de Taubaté demonstra uma anomalia no que diz respeito a relação causal imbricada na interpretação realizada por Singer, sendo de certa forma pouco explorada. O intuito desta análise, portanto, é buscar explicações para este fenômeno e com isso espera-se que a descoberta dos processos causais existentes neste caso possam elucidar outros casos que possam estar relacionados a este.

Com a finalidade de compreender o comportamento eleitoral desses eleitores estão sendo feitas entrevistas abertas e semi-estruturadas, de forma individual, com pessoas moradoras dos bairros Cecaps, em Taubaté- SP, e que também votem nesta mesma cidade.

$\mathrm{O}$ trabalho também opta pela etnografia. $\mathrm{O}$ uso de um método de trabalho característico da antropologia tem como intuito captar aspectos da

\footnotetext{
${ }^{2} \mathrm{O}$ levantamento foi feito com base no resultado das votações por seção. Os dados foram disponibilizados pelo Cartório Eleitoral - $407^{\mathrm{a}}$ Zona Eleitoral de Taubaté - SP.
} 
dinâmica da região que, como propõe José Guilherme Cantor Magnani (2002) poderiam passar despercebidos, se enquadrado somente pelo enfoque das visões macro e dos grandes números. Como o objetivo dessa pesquisa é compreender de forma mais profunda as problematizações e as percepções de mundo, sobretudo as políticas, desses moradores, assim como identificar as formas de convívio e sociabilidade existentes no Cecap, acredita-se que esse tipo de olhar seja o mais vantajoso.

O Cecap está localizado em uma região afastada da área central da cidade, sendo que o tempo de trajeto entre estes dois lugares, de carro, é de cerca de 25 minutos, com uma distância aproximada de $15 \mathrm{~km}$. O Cecap é formado por quatro bairros, todos levam o mesmo nome, o que os distinguem são os números no final do nome. Assim há o Cecap I, Cecap II, Cecap III e o Cecap IV.

A cronologia de estabelecimento e o nível de renda dos moradores de cada bairro parecem seguir a ordem numérica de cada bairro, visto que os habitantes que primeiro chegaram à região foram os do Cecap I, seguidos pelos do Cecap II e Cecap III e por fim pelos do Cecap IV.

O projeto de moradias na região teve o seu início na década de 70 , quando foi implementado pela Caixa Econômica Federal o CECAP (Companhia Estadual de Casas Populares), formando o atual Cecap I. Décadas mais tarde, em 1994, por meio da parceria entre prefeitura e CDHU (Companhia de Desenvolvimento Habitacional e Urbano do Estado de São Paulo), um segundo bairro foi construído com o intuito de sanar o déficit habitacional na cidade: o Cecap II.

Já os outros dois bairros são constituídos por prédios populares produzidos também pela prefeitura de Taubaté e pela CDHU, onde, de 
acordo com o site da Secretaria de Habitação do governo do estado de São Paulo, foram atendidas famílias que tinham renda de 1 a 10 salários mínimos.

\section{Desvendando a Região}

Os quatro bairros do Cecap, apesar de estarem quase que interligados, separados muitas vezes apenas por uma rua, têm aspectos bem diversos uns dos outros, sendo possível os diferenciar somente pelo olhar. A principal distinção é que os bairros mais antigos são formados por casas (sendo que o Cecap I é formado por sobrados e o Cecap II por casas térreas), enquanto os mais novos são compostos pelos prédios da CDHU.

As moradias dos bairros que se formaram antes são bem melhores estruturadas dos que os que foram construídas depois. Malgrado estarmos fazendo uma comparação entre casas e prédios padronizados,é possível ver uma discrepância na qualidade e na manutenção dos imóveis, enquanto encontramos no Cecap I e II algumas casas grandes e com aparência mais sofisticada, no Cecap III e IV os prédios já estão bem desgastados e sem pintura.

Assim como as moradias, as infraestruturas, o acesso a bens de consumo e os comércios também acompanham este raciocínio. Por exemplo, os pontos de lazer que estão mais próximos dos Cecaps III e IV estão bem depredados e sem qualquer manutenção. Já mais próximo aos outros dois bairros pode-se observar uma melhora nesta situação.

Da mesma forma, mesmo com um comércio incipiente na região, os principais pontos estão localizados em uma avenida próxima ao Cecap I, lá pode-se encontrar uma loja de sapatos, outras de roupas, casa lotérica e um supermercado, já nos outros Cecaps as lojas são menores, em sua maioria "barzinhos", mercearias, quitandas e açougues. 
Esta diferenciação não fica restrita às questões físicas, os próprios moradores dos bairros sentem e a exaltam.

\section{Perspectiva Política}

O modo como percebem a sua situação social está conectado às suas decisões políticas e eleitorais. A maioria do eleitorado da região, apesar de não ser politicamente informada, utiliza uma série de dados disponíveis no seu cotidiano, incluindo aqueles que foram formados a partir de fora, para decidir o seu voto. Ele principalmente busca escolher em quem votar tomando como base o seu meio social e as suas condições.

Contudo, deve-se advertir que, tendo em vista a abundância de elementos presente na nossa democracia, grande parte dos moradores do Cecap não tinha clareza de como a política brasileira funcionava e quem eram os seus principais atores políticos. O protagonismo recente e reiterado exercido em conjunto por PT e PSDB nas disputas eleitorais mais importantes acabou por tornar estes dois partidos os mais conhecidos e os mais votados no Cecap. Este predomínio é e foi sentindo principalmente no momento anterior ao das eleições, quando as questões políticas ainda não estavam presentes de forma intensa no cotidiano dos moradores.

Como apontado, na eleição de 2010, a então candidata à presidência pelo PT não obteve a melhor posição na região do Cecap, apesar disso, Lula e Dilma eram constantemente citados e lembrados durante as entrevistas. Com exceção do PT e do PSDB, dificilmente, os moradores que entrevistei conseguiam identificar tão rapidamente um político de algum outro partido. Neste sentido, era nítido como estas duas figuras são populares entre estes moradores, apesar de alguns ainda confundirem o nome de Dilma, não havia uma pessoa que dissesse não saber quem era Lula. 
Portanto, se a priori, como notamos anteriormente, pode-se argumentar que o lulismo não teve influência decisiva no processo eleitoral, após o início do trabalho de campo, nota-se o contrário, que na realidade muitos dos moradores demonstram certa preferência por Lula e Dilma e acabam muitas vezes por depositar o seu voto nestes candidatos. Isso significa dizer que o lulismo se faz sim presente entre os habitantes desta periferia e que há um certo laço que os liga, embora não se possa dizer que seja algo forte e duradouro.

Ainda, outro ponto que ajuda a salientar a grande adesão desta camada mais desfavorecida ao Lula e ao seu projeto político, além do trabalho de campo que está sendo realizado, é o resultado eleitoral por urnas na eleição de 2010 de outras regiões da cidade. ${ }^{3}$

Quando analisamos os votos tendo como base o local de votação, pode-se notar uma grande discrepância entre as porcentagens recebidas por cada candidato. Esta diferença é bem acentuada principalmente quando se toma como base os locais de votação que estão situados no centro da cidade.

O PT se mantém na escala dos $20 \%$ em locais de votação que estão no centro da cidade, já o PSDB possui uma força bem maior e vence com facilidade, tendo sempre mais de $40 \%$ dos votos (máximo de 47\%). Sendo assim, enquanto a diferença percentual entre Dilma e Serra no centro da cidade é bem larga, cerca de 20 pontos, na periferia do Cecap este número cai drasticamente, como apontado anteriormente (Página 1).

Apesar do PSDB continuar sendo o vitorioso no Cecap, a sua vantagem é bem menor ali, já que a votação do PT ganha força. Desta maneira, não se pode negar que o lulismo realmente não esteja presente

\footnotetext{
${ }^{3} \mathrm{O}$ levantamento foi feito com base no resultado das votações por seção. Os dados foram disponibilizados pelo Cartório Eleitoral - $407^{\mathrm{a}}$ Zona Eleitoral de Taubaté - SP.
} 
naquela região, apesar de aparentemente latente. Em contrapartida, deve-se ter claro que também existe um grupo, em maior número, que está optando por pelo candidato da oposição. Dizer isto, porém, se elucida alguns pontos, suscita outros, uma vez que traz para o debate a questão de saber quem são esses e aqueles eleitores e por quais motivos decidiram votar no PSDB e no PT, respectivamente.

\section{Comportamento Eleitoral e a Eleição de 2014}

É possível verificar que a maioria das pessoas do Cecap acredita que Lula defende (o que prossegue com Dilma) os interesses sociais dos mais pobres, uma vez que as suas políticas são voltadas, em suas concepções, para aqueles que têm maior carência financeira. Os entrevistados, até mesmo aqueles que afirmam que não foram beneficiados diretamente por elas (já que todas as suas conquistas foram por conta própria), aprovam as ações governamentais de distribuição de renda proferidas pelo governo Lula durante os seus mandatos, pois percebem o quanto este tipo de iniciativa é importante para os que necessitam.

E o que explica a força do PSDB no bairro? Esta é ainda uma questão que ainda vem sendo aprofundada, todavia, pode-se destacar, que ao mesmo tempo que alguns atributos pessoais dos candidatos do PT são também lembrados (como Lula já ter passado pelo o que eles passam, de conhecer a realidade da miséria, de ter vindo do nordeste $)^{4}$, o eleitor, igualmente considera outras características, só que desta vez em teor negativo, como falta de honestidade e credibilidade.

Porém se o PT é o partido mais conhecido, os indícios de corrupção sobre o partido também acabam tendo maior impacto na percepção destes

\footnotetext{
${ }^{4}$ Atributos que estão vinculados à agenda política voltada para os mais pobres.
} 
eleitores. É verdade que há uma generalização entre os entrevistados de que a política está cheia de "roubalheira" e que não existe político honesto, mas como Lula e Dilma são os mais populares, a associação deles com a corrupção acaba sendo mais forte e as suas imagens ficam mais manchadas.

O PT passa a ser visto então como uma figura ambígua, se ele é o único partido que intercede pelos mais pobres, também é visto como a sigla que está no meio das falcatruas da política. Indica-se que, essencialmente entre este divisor de águas, se estabelece a visão dos moradores da região do Cecap. Apesar de aprovarem as políticas do governo Lula e de Dilma e de alguns terem sido até beneficiados por elas, alguns deles optaram por votar no PSDB.

As entrevistas tendem a sugerir, até o momento, que estas pessoas que possuem preferência pelos candidatos oposicionistas o fazem devido ao escândalo de corrupção, principalmente o mensalão, pelo qual o PT estaria ligado. As pessoas com que conversei se mostraram decepcionadas com a atuação de Lula e de Dilma, o que teria as feito perderem a confiança nestes políticos.

Neste sentido, é possível perceber que o voto no PSDB na periferia do Cecap tende a se aproximar com os das classes médias da cidade de Taubaté, que como ficou em certa medida demonstrado na tabela 2, têm uma maior unidade em torno desse partido. De acordo com Singer (2009, 2012), as classes médias tenderam a deslocar o seu voto para o PSDB por conta das denúncias de corrupção feitas pelo PT, do mesmo modo, parece que parte dos eleitores da região do Cecap segue os mesmos pressupostos para deixar de depositar na urna o voto no PT.

No entanto, o quadro partidário não ficou centrado nestes dois partidos no momento em que a campanha começou a ir às ruas. Exatamente por serem 
o PT e o PSDB os partidos que frequentemente têm mais chances nas disputas e por estarem, na visão dos moradores, sempre no comando da política, muitos dos eleitores, um número de modo algum pequeno, vêm buscando uma terceira alternativa, que no caso foi encarnado pela figura da Marina. Os eleitores que tinham o intuito de depositar o voto nesta candidata declararam que a sua decisão estava pautada no fato dela representar uma mudança no cenário político.

Marina parece conseguir capitalizar o voto daqueles que estavam descrentes com a política. A opção pela sua candidatura, portanto, simboliza em certa medida a hostilidade dos moradores com o modo que a política vem sendo conduzida.

A candidata ao se debruçar sobre questões amplas e difusas durante a sua campanha eleitoral de 2014, sem apresentar uma plataforma política bem definida, acabou por criar um mecanismo que facilitou a neutralização das clivagens socioeconômicas. Como pode ser notado, o voto em Marina não foi devido a algum tipo de proposta que ela apresentou e nem mesmo por causa da percepção que ela iria se centrar sobre os anseios de uma classe em específico.

Dentro do Cecap I, II, III e IV, as pessoas que tinham condições financeiras maiores pareciam ter uma maior propensão a optar pela candidata, porém, para este caso, aparentemente o status econômico não foi o principal determinante do comportamento eleitoral, já que moradores com as mais diversas situações socioeconômicas mostraram ter a intenção de depositar o seu voto na candidata.

Palavras Chave: Periferia, Taubaté-SP, Voto, Comportamento Eleitoral, Trabalho de Campo 


\section{Referências}

ADIB, Irene V. de L. (2001). Cecap III: uma construção coletiva para programas da terceira idade. Trabalho de conclusão do curso de Serviço Social, UNITAU, Taubaté.

ALBUQUERQUE, José A. Guilhon (1992). "Identidade, oposição e pragmatismo: uma teoria política do voto", Lua Nova, n. 26, pp.53-79

BEACH, Derek e PEDERSEN, Rasmus Brun (2012). Process-tracing Methods: Foundations and Guidelines. University of Michigan Press.

BENNETT, A. (2004). "Case Study Methods: Design, Use, and Comparative Advantages". In: SPRINZ, D. F. \& WOLINSKY-NAHMIAS, Y. (eds.). Models, Numbers, and Cases: Methodsfor Studying International Relations. Ann Arbor: University of Michigan.

BRADY, E. Henry. (2008). "Causation and Explanation in Social Science". In: BOXSTEFFENSMEIER, Janet M.; BRADY, Henry; COLLIER, David (eds). The Oxford Handbook of Political Methodology. Oxford: Oxford University Press, pp. 217-249.

BRITO, M. L. J. D. (2011). O comportamento eleitoral no Brasil: Uma análise das principais pesquisas e do debate (1989- 2006). Trabalho de conclusão do curso de Ciências Sociais, UNIFESP, Guarulhos.

BUENO, Daniella G. (2006). Opinião dos adolescentes sobre o programa Escola da Família: bairro Cecap - Taubaté. Trabalho de conclusão do curso de Serviço Social, UNITAU, Taubaté.

CALDEIRA, Teresa Pires do Rio (2000). Cidade de muros: crime, segregação e cidadania em São Paulo. São Paulo: Editora 34; Edusp.

COMPANHIA DE DESENVOLVIMENTO HABITACIONAL E URBANO DO

ESTADO DE SÃO PAULO. Disponível em:

<http://www.cdhu.sp.gov.br/cdhu/index.asp >. Acesso em: 17/03/2012.

COSTA, Letícia Maria Pinto da (2007). Na contramão do Marketing Político: As eleições Municipais de Taubaté-SP, em 2004. Tese de Doutorado em Comunicação Social, UMESP, São Bernardo do Campo.

COSTA, S. L (2005). Taubaté, o Local e o Global na construção do desenvolvimento. Taubaté, SP: Cabral Editora e Livraria Universitária.

FELTRAN, Gabriel (2011). Fronteiras de Tensão: Política e Violência nas periferias de São Paulo. São Paulo: Editora Unesp: CEM: Cebrap.

FIGUEIREDO, Marcus (1991). A decisão do voto: Democracia e racionalidade. São Paulo: Editora Sumaré/Anpocs 
FREIRE, André (2001). Modelos do comportamento eleitoral: uma breve introdução crítica. Oeiras: Celta.

FREITAS, Vânia B. (2002). O adolescente do Cecap III: Possibilidades ou sonhos. Trabalho de conclusão do curso de Serviço Social, UNITAU, Taubaté.

GERRING, J (2004). "What Is a Case Study and What Is It Good for?", American Political Science Review, Los Angeles, v. 98, n. 2, p. 341-354, Maio. Disponível em: http://web.rollins.edu/ ddavison/Spring08/Gerring_CaseStudies.pdf.

LAMOUNIER, Bolívar (1989). Partidos e Utopia: O Brasil no limiar dos anos 90. São Paulo: Loyola.

MAGNANI, José Guilherme C. (1998). Festa no pedaço: cultura popular e lazer na cidade. São Paulo: Hucitec.

(2002). "De perto e de Dentro: notas para uma etnografia urbana". In: Revista Brasileira de Ciências Sociais, Anpocs, vol. 17, n.49, PP.11-30.

(2012). Da periferia ao Centro: trajetórias de pesquisa em Antropologia Urbana. São Paulo: Editora Terceiro Nome, Coleção Antropologia Hoje.

MARCONDES, Joelma N. (2003). A construção da metodologia interventiva em serviço social: Um estudo exploratório da ação do serviço social no projeto Cecap III. Trabalho de conclusão do curso de Serviço Social, UNITAU, Taubaté.

MELO, Salvador S. (1998). Política habitacional e cidadania: a questão dos equipamentos e serviços sociais do entorno, UNITAU, Taubaté.

PIERUCCI, Antônio Flávio (1987). As bases da nova direita. Novos Estudos. CEBRAP, São Paulo, SP, n.19, p. 26-45.

PIERUCCI, Antônio Flávio (1989). A direita mora do outro lado da cidade. Revista Brasileira de Ciências Sociais, v. 4, n.10, p. 46-64.

PIERUCCI, Antônio Flávio (1999). Ciladas da diferença. São Paulo: Editora 34.

PIERUCCI, Antônio Flávio; LIMA, M. C (1991). A direita que flutua: O voto conservador na eleição de 1990 em São Paulo. Novos Estudos. CEBRAP, São Paulo, SP, n.29, p. 10-27.

PIERUCCI, Antônio Flávio; LIMA, M. C (1993). São Paulo 92: A vitória da direita. Novos Estudos. CEBRAP, São Paulo, n.35, p. 91-99.

RAGIN, Charles C (1987). The comparative method: moving beyond qualitative and quantitative strategies. Berkeley: University of California Press. 
REIS, Fábio Wanderley (1978). Os Partidos e o Regime: A lógica do processo eleitoral brasileiro. São Paulo: Símbolo.

SEANWRIGHT, J e GERRING, J (2008). Case selection techniques in case study research. Political Research Quartely 61(2):294-308

SINGER, André (2002). Esquerda e direita no eleitorado brasileiro: a identificação ideológica nas disputas presidenciais de 1989 e 1994. São Paulo: Editora da Universidade de São Paulo.

(2009). "Raízes sociais e ideológicas do lulismo", Novos Estudos Cebrap, n.85, pp. 83-102.

(2012). Os sentidos do lulismo: reforma gradual e pacto conservador. São Paulo; Companhia das Letras.

TRIBUNAL SUPERIOR ELEITORAL. Disponível em: <http://www.tse.jus.br>. Acesso em: 14/08/2012.

VAN WYNSBERGHE, R. e KHAN, S (2007). "Redefining Case Study". International Journal of Qualitative Methods, Edmonton, v. 6, n. 2, p. 80-94. Disponível em: http://ejournals.library.ualberta.ca/index.php/IJQM/article/view/542/2495.

YIN, R. K (2009). Case Study Research: Design and Methods. Thousand Oaks: Sage. 